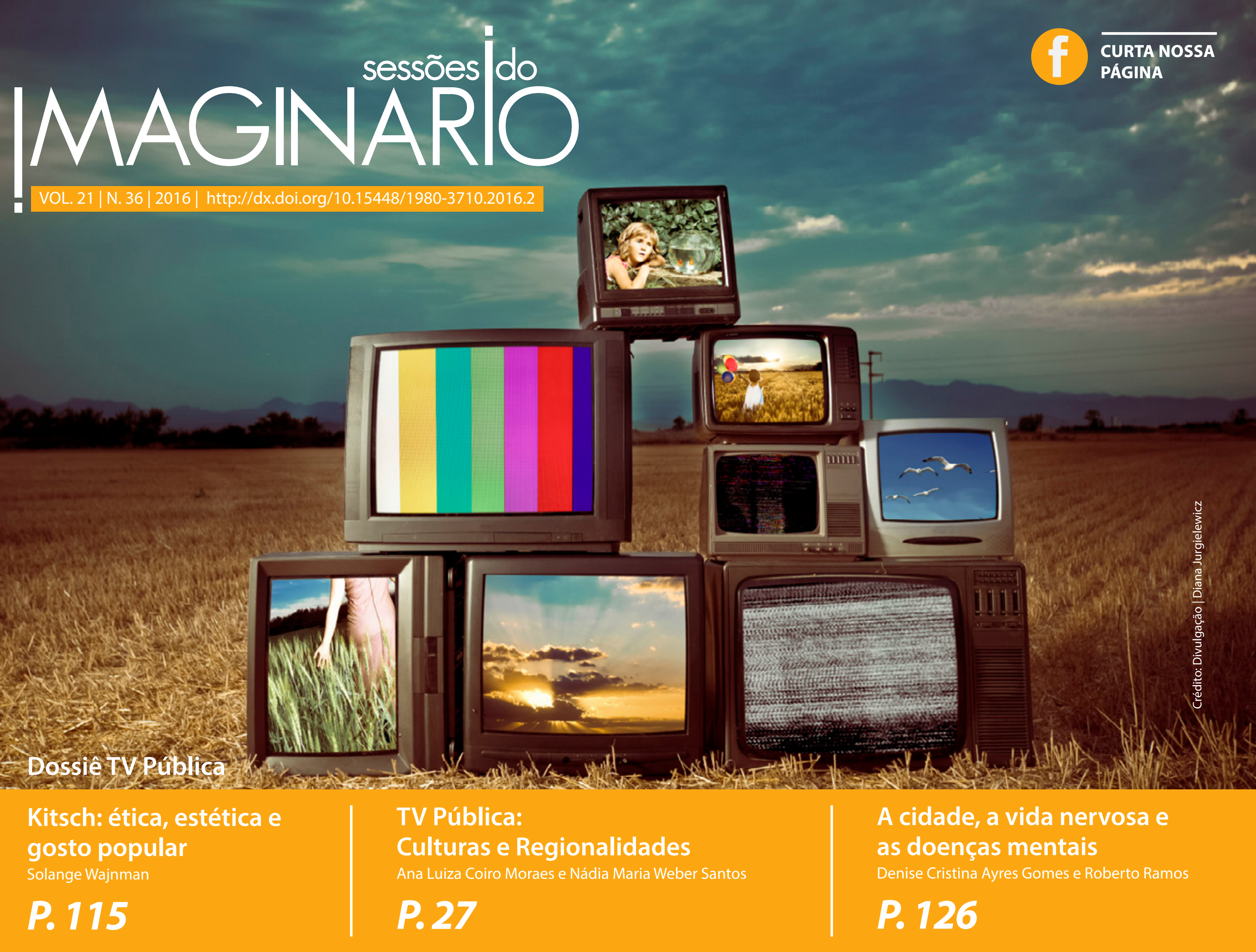




\section{Pedaços de maus}

caminhos: o belo e o grotesco nas representações das cidades no telejornalismo brasileiro

\section{Pieces of bad roads: the beautiful} and the grotesque in the representations of cities on brazilian television journalism

\section{Ana Carolina Rocha Pessôa Temer ${ }^{1}$} Simone Antoniaci Tuzzo²

\section{AUTORAS CONVIDADAS}

\section{Resumo}

A base teórica para reflexão neste trabalho diz respeito às rotinas produtivas, à questão dos valores-notícia e ao conceito de ethos escatológico da cultura, desenvolvido pelo pensador Muniz Sodré, buscando entender o modo que as representações do grotesco se impõem como um modelo estético presente no telejornalismo. Neste princípio, esta pesquisa busca contrapor dois conteúdos exibidos no telejornal Bom Dia Brasil, em duas sextas-feiras consecutivas, mas cujo conteúdo difere não apenas nos aspectos relativos a sua seleção - valores-notícia - mas também na forma pela qual retratam o espaço urbano. Observa-se que o telejornalismo cria um mapa urbano diferenciado, a cidade acolhedora, da classe média alta e das belas paisagens, e a cidade não acolhedora, dos pobres e desvalidos, colocando em questão o próprio conceito de cidadania.

\section{Palavras-chave}

Televisão; jornalismo; telejornal; Muniz Sodré; grotesco.

\section{Abstract}

The theoretical basis for reflection in this work refers to production routines, the question of news values and the concept of eschatological ethos of culture, developed by thinker Muniz Sodré, seeking to understand the way that the representations of the grotesque are imposed as an aesthetic model present in television news. In this way, this research seeks to counter two contents displayed on the television news Bom Dia Brasil, on two consecutive Fridays, but whose content differs not only in the aspects of your selection - news values - but also in the way they portray the urban space. We can observe that the TV news creates a distinctive urban map that puts the one hand, a welcoming city, the average high and beautiful scenery class, and on the other hand a non-welcoming city of poor and underprivileged people, putting in question the concept of citizenship.

\section{Keywords}

Television; journalism; television news; Muniz Sodré; grotesque.

17 PORTO ALEGRE | v. 21 | n. 36 | 2016 | pp. 17-26 DOI: http://dx.doi.org/10.15448/1980-3710.2016.2.25850 Sessões do Imaginário 


\section{Introdução}

Na quinta-feira, dia 21 de março de 2016, feriado nacional no Brasil, a população brasileira foi surpreendida e informada sobre a queda de um trecho da Ciclovia Tim Maia, que circunda a topografia acidentada da Avenida Niemayer na cidade do Rio de Janeiro. A notícia repercutiu no decorrer do dia e, é claro, foi objeto de uma extensa reportagem - mais de sete minutos - no telejornal Bom Dia Brasil na manhã seguinte, sexta-feira, dia 22 de março, que teve como retranca Engenheiros apontam falhas graves em ciclovia que desabou no Rio $^{3}$.

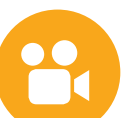

\section{ASSISTA AO VÍDEO}

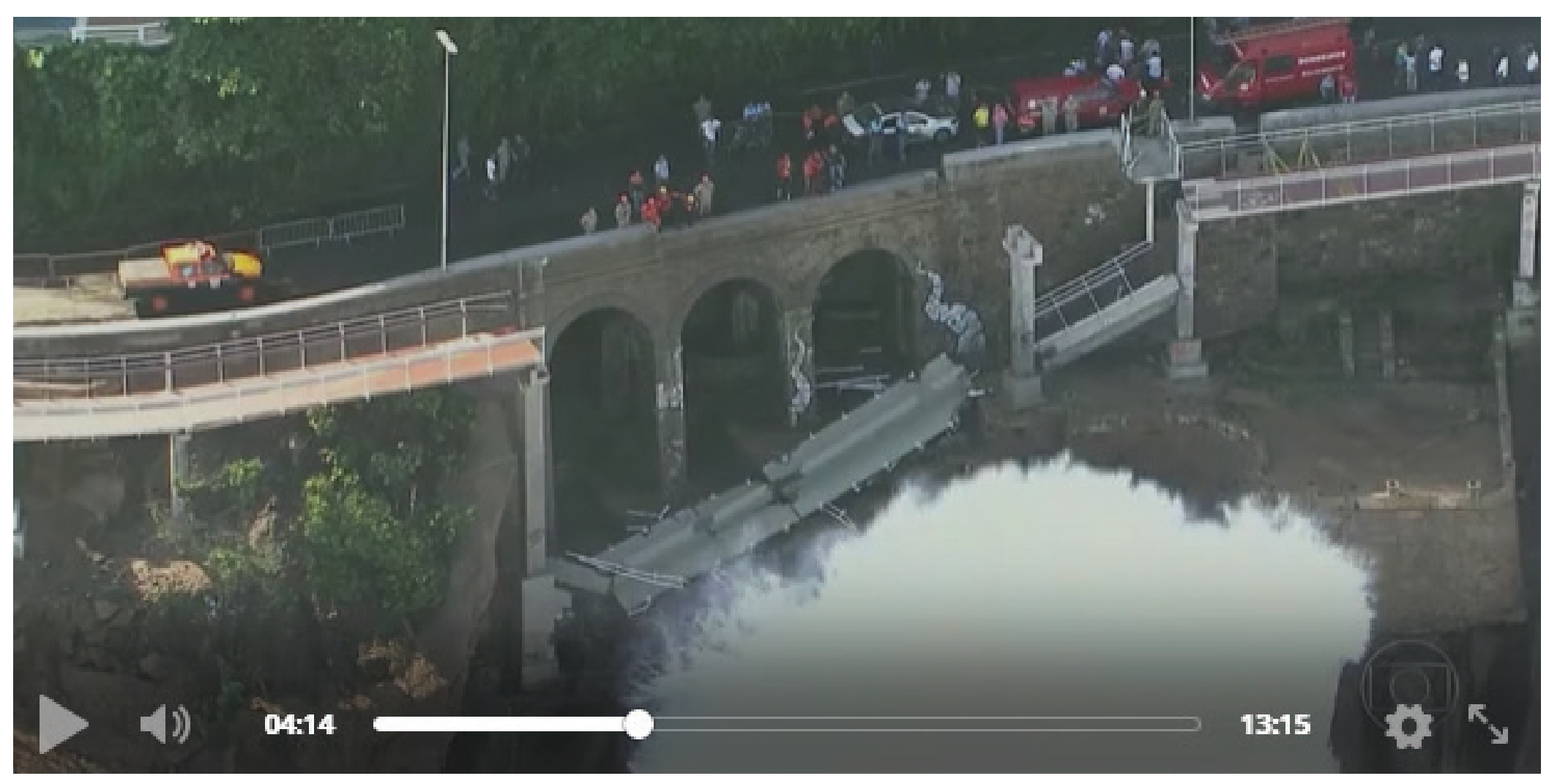

A reportagem observou os critérios de qualidade já instituídos pela Rede Globo de Televisão, assim como as características básicas do telejornal Bom Dia Brasil, o que inclui o uso de efeitos especiais com a reconstituição do acidente, a presença de especialistas e comentaristas, conteúdos colaborativos (cenas do momento do acidente) capturados por dispositivos móveis particulares de pessoas que passavam pelo local, declarações dos políticos, insinuações sobre corrupção e nepotismo na execução da obra e um conjunto de imagens do local, mas se destaca também pela qualidade das imagens elemento importante e cuidadosamente trabalhado no telejornalismo da Rede Globo de Televisão - que neste caso específico voltou-se para a plasticidade e beleza daquela região carioca, mas também a uma gentil exibição das praias e transeuntes da região.

O modelo de reportagem, com seus elementos básicos - entre eles o cuidado com a qualidade das imagens - estão também presentes em uma segunda reportagem, igualmente objeto de análise neste trabalho, exibida uma semana antes, no dia 15 de abril, no mesmo telejornal. A matéria, cuja retranca é Calçadas mal-conservadas dão origem a campanha pelo país ${ }^{4}$, não aborda uma questão factual, mas faz eco a uma campanha Calçada-Cilada, veiculada na internet pelo grupo autointitulado Corrida Legal, que denuncia a péssima qualidade das calçadas e espaços para tráfego de pedestres nas cidades brasileiras.

Analisadas de forma comparativa, as duas reportagens apontam que a tarefa básica do jornalismo, a narrativa dos fatos/acontecimentos, envolve estratégias que são ao mesmo tempo racionais e sensíveis (Sodré, 2009, p. 09), escolhas de pautas, enquadramentos e linguagens condicionadas pela percepção dos produtores midiáticos do espaço físico - o locus urbano - no qual é colhida a informação. $O$ trabalho desenvolvido aqui pretende apontar como o telejornalismo da Rede Globo de Televisão, e em particular o telejornal Bom Dia Brasil, ao ser atravessado por interesses econômicos, sociais e políticos diversos, constrói ou reforça um mapeamento urbano particular, construindo concomitantemente dois espaços, duas cidades: a cidade acolhedora - bonita e habitável, dos turistas e das classes média-alta e alta; e a cidade não acolhedora, o espaço do trabalho, do trânsito e, sobretudo, daqueles com menor poder aquisitivo. Esse segundo espaço, mais do que diferenciado pelo status ou

18 PORTO ALEGRE | v. 21 | n. 36 | 2016 | pp. 17-26 Sessões do Imaginário 
pelo uso, é também diferenciado por meio da introdução do grotesco, do feio, do escatológico e da negação da própria civilidade, e por extensão, da cidadania.

A proposta deste trabalho é analisar de forma comparativa duas possibilidades de narrativa, a partir dos elementos que determinam a construção da pauta jornalística, os critérios de noticiabilidade e valores-notícia, mas também por meio da compreensão da utilização de uma estética que vai além da visualidade, e se coloca como elemento definidor de uma realidade narrada: o grotesco.

A partir desta proposta, a metodologia utilizada envolve uma análise comparativa do material jornalístico citado, mas também um olhar crítico sobre o conteúdo de um modelo de telejornalismo, que se consolidou a partir do uso estratégico de visualidades, mas que vem sofrendo quedas acentuadas de audiência e que, em busca de manter seu status, tem ampliado o espaço na abordagem de conteúdos policialescos e na cobertura das mazelas urbanas, além de trabalhar com cada vez mais constância as pautas obtidas por meio da observação das redes sociais.

Como resultado busca-se não apenas lançar luzes sobre esse modelo de telejornalismo, mas também sobre o uso do grotesco e a aproximação estratégica do telejornalismo com o gosto popular, enquanto tática para conquista de um público antes pouco valorizado. Em um sentido amplo, buscou-se compreender de que forma o telejornalismo, mais do que informar, procura surpreender e reforçar um mapeamento urbano fundamentado em uma negatividade estética, apresentando aos seus receptores a negação da cidadania.

A partir da análise comparativa, conclui-se que o uso estratégico do grotesco corrobora os interesses da emissora na representação de uma cidade não acolhedora,

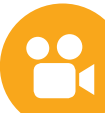

\section{ASSISTA AO VÍDEO}

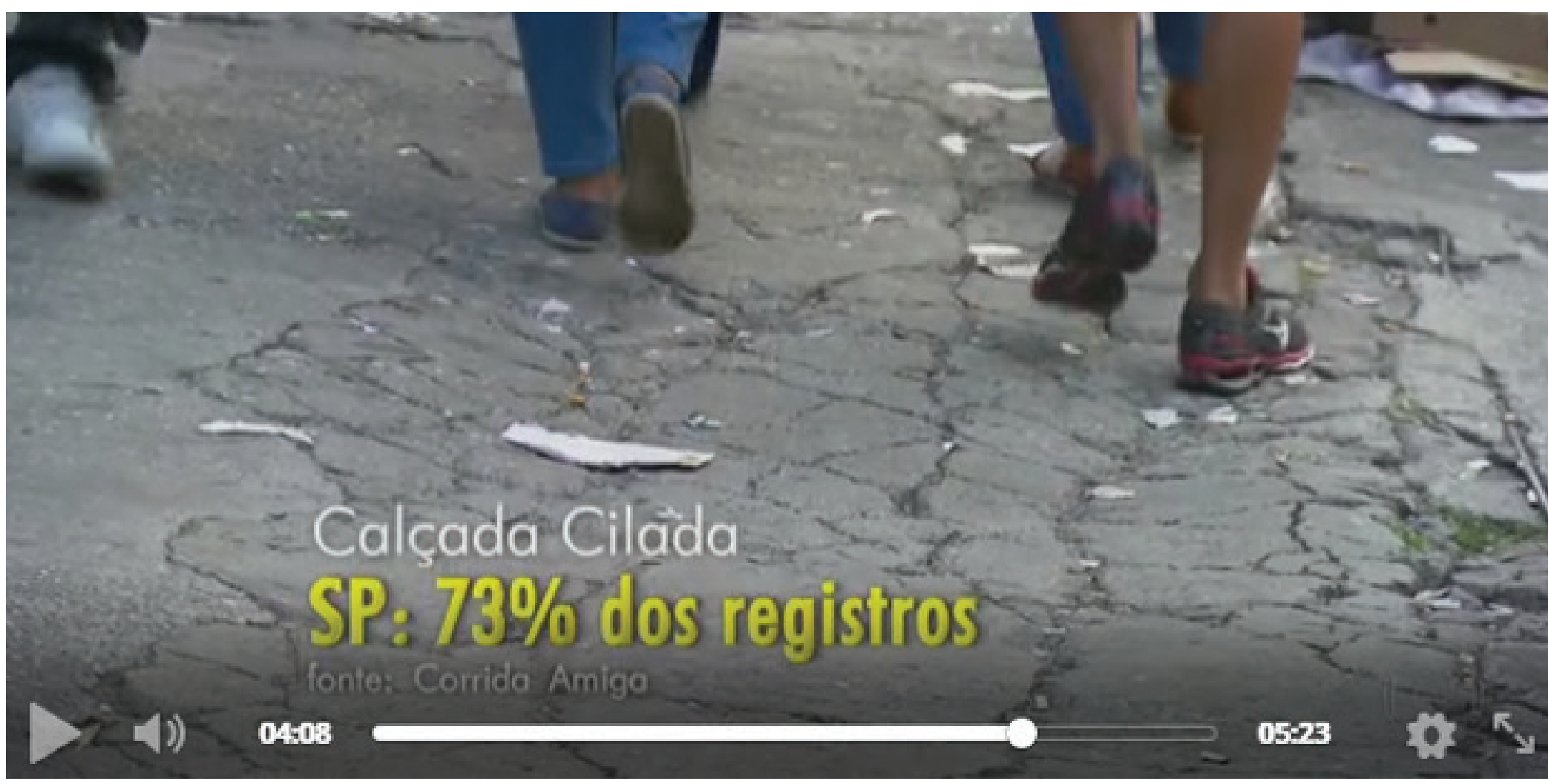

cujos sintomas vão além da violência da contravenção, e passam também pela destruição ou desmantelamenrevistas científicas e entrevistas veiculadas na TV e na Internet. O grotesco está na sociedade e não há societo dos espaços públicos, pela anarquia urbana, e outros fatores.

\section{O grotesco como rotina em} uma sociedade complexa

Este trabalho privilegia um olhar sobre as formas grotescas que exacerbam na televisão e que são profundamente discutidas pelo pensador Muniz Sodré (1973, 2002) em vários estudos publicados em livros, dade sem comunicação, como afirma Sodré em seu primeiro ensaio sobre o grotesco em 1973. Para ele também é importante a relação entre o grotesco e a cultura de massa, que num primeiro momento por ser pensada em oposição à cultura superior, a erudita, mas "esta oposição é basicamente falsa, porque o código da cultura de massa é ontologicamente o mesmo da cultura elevada, apenas adaptado para o consumo de todas as classes sociais" (Sodré, 1973, p. 16) 
Assim, a relação entre o grotesco, a sociedade e a comunicação são eixos de pensamento deste trabalho que ao firmar-se em Sodré importante destacar o ethos escatológico da cultura de massa, em que a televisão ainda é sua maior referência e produto.

Aqui vale considerar se as escatologias que geraram figuras mitológicas e também espetaculares para o cinema, o circo e para a televisão continuam a gerar formas de espetáculo a ser exibido em troca de algum dinheiro ou de alguma fama. Sodré afirma que:

O ethos da cultura de massa brasileira, tão perto quanto ainda se acha da cultura oral, é fortemente marcado pelas influências escatológicas da tradição popular. O fascínio pelo extraordinário, pela aberração, é evidente nos programas de variedades. A essa altura, a escatologia consegue juntar os dois sentidos: o místico e o coprológico (Sodré, 1973, p. 38).

E, ainda que seja absolutamente tranquilo observar que as palavras de Muniz Sodré escritas em 1973 encontram ainda mais eco nos dias atuais, o próprio autor atualiza suas ideias dentro do mesmo raciocínio quando afirma que "desde meados da década de 90, as aberrações recrudesceram na televisão brasileira" (Sodré e Paiva, 2002, p. 13).

Mas esse espetáculo midiático não pode ser compreendido por si só, como Sodré mesmo afirma, "[...] o grotesco é posto a serviço de um sistema que pretende ser exatamente a compreensão para a angústia do indivíduo dos grandes agrupamentos urbanos" (Sodré, 1973, p. 39).

Desta forma, esta visão deve ser compreendida na complexidade social estudada por Morin (2005, p. 180) que entre as várias reflexões sobre o assunto, também coloca a questão no âmbito organizacional/social e que pode ser pensado na relação entre a sociedade e a televisão. Segundo o autor:

A organização é aquilo que constitui um sistema a partir de elementos diferentes; portanto, ela constitui, ao mesmo tempo, uma unidade e uma multiplicidade. A complexidade lógica de unitas multiplex nos pede para não transformar o múltiplo em um nem o um em múltiplo (Morin, 2005, p. 180).

Desta forma, o grotesco na televisão se altera com relação à sua forma, profundidade e grau de perplexidade, assim como o grotesco nas relações sociais também se altera com o passar dos anos, com a localização geográfica, com a complexidade das relações sociais.

Os níveis de aceitação do grotesco também se alteram, como são mutáveis os graus de aceitação nas relações pessoais. Morin, ao fazer uma relação entre a complexidade pessoal e social afirma que:

[...] ao nível de complexidade organizacional, precisamos acrescentar um nível de complexidade própria às organizações biológicas e sociais. Essas organizações são complexas, porque são, a um só tempo, acêntricas (o que quer dizer que funcionam de maneira anárquica por interações espontâneas), policêntricas (que têm muitos centros de controle, ou organizações) e cêntricas (que dispõem, ao mesmo tempo, de um centro de decisão). Desse modo, nossas sociedades históricas contemporâneas se auto-organizam não só a partir de um centro de comando-decisão (Estado, governo), mas também de diversos centros de organização (autoridades estaduais, municipais, empresas, partidos políticos etc.) e de interações espontâneas entre grupos de indivíduos (Morin, 2005, p. 180).

\section{O jornalismo e o grotesco}

Desde sua origem como mecanismo de sistema social burguês e capitalista, o jornalismo tem como loccus privilegiado o espaço urbano, que por sua vez é tanto local da produção e reprodução do capital (Engels, 1985) ${ }^{5}$, quanto um laboratório social' ${ }^{6}$ (Park, 1987) "[...] marcadamente mais rápido, caótico, fragmentado e desorientador [...]" (Singer, 2001, p. 96) que outras aglomerações sociais características da sociedade humana.

Neste ambiente, o jornalismo assume função de elo entre classes, grupos sociais e interesses diversos, por meio da narrativa da contemporaneidade - a ordenação do presente por meio da narrativa dos fatos reais?. Essa definição, ainda que incompleta, remete a outra; o jornalismo trabalha com fatos que fogem ao previsível, alteram a normalidade, interferem na organização social (ordem pública).

Temos assim que o jornalismo é uma atividade e um ator social - uma vez que interfere na vida social - cuja base capitalista exige a elaboração de um produto ao mesmo tempo regular e palpável, mas cuja base produtiva - a dinâmica social e seus entraves - não são previsíveis ou palpáveis. A base desse produto - ou pelo menos o pilar sobre o qual se apoia (sua alma ${ }^{8}$ ) é a notícia verdadeira, termo que remete a fatos reais novos ou desconhecidos, de grande impacto e de interesse público?.

Assim, cabe à imprensa denunciar tudo que foge à ordem urbana idealizada - trabalhando no sentido de 
manter/organizar a vida na urbe. Mas sua continuidade ou permanência depende de fazê-lo oferecendo-se como produto atraente e necessário, algo essencial para a vida e para os negócios e para a manutenção de um modelo de democracia igualmente idealizado. Sendo produto, o jornalismo deve estar disponível, ser disponibilizado, em intervalos regulares (periódicos) que o permitam ser em uma mesma lógica sempre o mesmo (modelo facilmente descodificável) e sempre novo ou repleto de informações novas, transformando a informação em mercadoria sedutora não apenas em função de seu conteúdo, mas também em função de apelos estéticos, emocionais e sensacionais.

As contingências desta produção têm elementos conflitantes e contraditórios. O aspecto fundamental que distingue a narrativa do telejornalismo de outras narrativas televisivas é o seu vínculo verdade. A verdade existe no jornalismo como meta desejada, e o compromisso com "dizer a verdade" é o discurso por meio do qual o jornalismo e os jornalistas se autodefinem. No entanto, ao mesmo tempo em que é registro, o jornalismo é construído a partir de relatos, "estórias", narrativas escolhidas pelos jornalistas organizados de forma a compor "[...] uma realidade construída possuidora de sua própria validade interna" (Tuchman, 1999, p. 262). A base destes relatos é a novidade, a imprevisibilidade, portanto o jornalismo, e em particular a notícia, carrega consigo um alto "teor de irrealidade", ou impactos que, desconstroem "o próprio teor de realidade do restante do mundo" (Seligmann-Silva, 2005, p. 69, grifo original).

Assim, por ser ao mesmo tempo uma surpresa e um rompimento da previsibilidade, a notícia carrega um alto potencial para o grotesco: os acidentes com os corpos destroçados, os atos terroristas e os danos que trazem consigo são, de muitas formas, manifestações grotescas de um tipo de barbárie que afeta a civilização Essa relação torna-se mais visível no telejornalismo popular sensacionalista que, com a sua propensão ao bizarro e ao vulgar, impõe as representações grotescas a partir de uma dupla perspectiva: como estratégia para chamar a atenção, uma vez que surpreende os sentidos; mas também como caminho para conquistar um conjunto de receptores que, por vários motivos, se sentem alijados do modelo estético dominante.

Seria um engano pensar, no entanto, que o grotesco está presente apenas na representação do factual ou no jornalismo popular sensacionalista. O retrato do grotesco contamina o conjunto do telejornalismo a partir das representações de outros espaços, em uma relação que exige outro tipo de reflexão: a notícia, matérias súbitas ou factuais ${ }^{10}$, o imprevisível, que somente tem sentido quando destacado em oposição ao previsível ou normal. Dessa forma, o telejornalismo trabalha com o que foge à normalidade, mas para fazer isso necessita de um primeiro movimento: a construção da normalidade.

Na televisão brasileira essa normalidade, ou seja, a rotina, o cotidiano, é em grande parte construída pela telenovela, que não por acaso é também exibida nos horários que se avizinham ao telejornalismo, principalmente nos períodos classificados como horário nobre ${ }^{11}$. Ainda assim, a contribuição do telejornalismo para a construção dessa normalidade é também significativa. Isso ocorre por meio das chamadas matérias em desenvolvimento ou em sequência, mas também pelas matérias leves ${ }^{12}$, material cujo conteúdo é voltado para a prestação de serviços, comentários sobre o tempo e o trânsito etc.

Esse material, cuja presença no telejornalismo nunca foi insignificante, tem ganhado novas expressões em períodos mais recentes, pois tem se somado a ele as denúncias sobre mazelas urbanas e a incompetência dos gestores em cuidar dos espaços públicos (e, em particular, dos espaços urbanos), além de deficiências em setores nos quais a atuação do Estado é essencial, como por exemplo, transporte, segurança, educação, saúde, atendimentos públicos diversos.

Neste sentido, ao inserir uma proposta de analisar duas matérias jornalísticas diferenciadas, questiona-se aqui se o potencial para o grotesco presente na notícia é replicado ou mesmo ampliado nas matérias leves ou sequenciais, contaminando e reforçando uma visão negativa de alguns espaços urbanos.

\section{Revendo o material analisado}

A primeira matéria analisada, sobre a (má) qualidade dos passeios se enquadra na categoria de denúncia. $O$ material tem claramente origem em um conteúdo produzido pela central de telejornalismo da Rede Globo em São Paulo, local retratado na maior parte das cenas, mas ganha mais representatividade e dinamismo cinético com a inclusão do material gravado por diferentes emissoras da rede (Recife, Rio de Janeiro e Goiânia) e a inclusão de material colaborativo, enviado pela emissora, mas principalmente capturado nas redes sociais, com destaque para o material fornecido pelo grupo Corrida Legal. A matéria tem seu ponto de maior apelo ao falar da má qualidade da calçada "em frente ao Instituto da Criança" caminho para o Hospital das Clínicas em São Paulo, maior complexo hospitalar da América Latina. A qualidade do material segue o padrão do telejornalismo da emissora, com alternância de texto em off, entrevistas e passagem do repórter, sempre com boa qualidade fílmica e até mesmo com eventuais audácias no enqua- 
dramento, como a filmagem das calçadas na altura das próprias calçadas, realçando os desníveis.

No entanto merece ser destacado que o tom de denúncia esconde a obviedade do que é dito, pois a má qualidade das vias públicas no Brasil, particularmente nas regiões mais populares, não é uma surpresa. Trata-se de segredo de Polichinelo ${ }^{13}$, elemento reforçado pela própria apresentadora do telejornal (Ana Paula Araújo), que comenta que, ao falar da má qualidade das calçadas, reforça que esse é um fato que a gente conhece bem. No entanto, o assunto é colocado em tom de indignação, de grave quebra da normalidade que adquire uma narrativa de notícia.

A matéria, que termina com as justificativas-padrão das Prefeituras das cidades apresentadas, ganha reforço pelos comentários dos apresentadores, "de que procura-se desesperadamente uma calçada em bom estado", e a resposta do noticiarista/apresentador (Chico Pinheiro) de que se trata de verdadeiros "pedaços de mau caminho".

A estratégia de espetacularizar matérias de pouco impacto não é nova. Utilizada com certa frequência, o bastante para que seu impacto não se perca totalmente, reforça o teor relevante de grotesco da cidade/ calçada apresentada na reportagem. A calçada cilada torna-se a negação da cidade/civilidade: é o passeio que não convida ao andar, a cidade que machuca (nos depoimentos, são ressaltados quedas e até ferimentos decorrentes da má qualidade das calçadas) em vez de acolher. No entanto, essa relação trai também uma questão definidora desta proposta de reportagem: uma abordagem jornalística que pulveriza as questões coletivas, colocando-os como pequenos inconvenientemente pontuais, quando não raros.
O fato também se evidencia por meio de uma das características do jornalismo-telejornalismo, é que a reportagem construída a partir do relato de "testemunha", aquele que viu com seus próprios olhos, e que tendo visto possibilita ao jornalista ser outro tipo de testemunha, aquele que leva adiante a história do presente. Elemento essencial ao jornalismo, essas testemunhas são também a fala obliterada, reconstruída pela edição, sufocada por um relato mais amplo, o relato jornalístico como forma de re-temporalizar no presente.

Aos elementos grotescos da narrativa sobre a cidade negada, soma-se a presença da jornalista composta e bem-arrumada, cuja presença se dá em evidente contraponto aos pedestres atarantados, indignados, carentes de atenção do poder público. Em oposição a essa fala minimizada das testemunhas, temos a fala destacada da repórter (a autoridade-autoritária), cujo discurso enfático encarna a representação da lógica, do pedido justo, da civilidade das classes privilegiadas tentando se impor ao grotesco das periferias ou das zonas esquecidas pelo poder público.

A segunda matéria se insere no conceito de matéria dura e factual, diz respeito a um fato súbito, no caso o desabamento de um pedaço de uma passarela para ciclistas recentemente construída e inaugurada. A obra, apresentada como parte das adaptações urbanas para receber turistas e atletas para as Olimpíadas 2016, se insere em um espaço urbano privilegiado, bairro para onde afluem moradores de melhor poder aquisitivo (embora ensombrados pela proximidade de uma favela, fato negligenciado na reportagem aqui analisada), deslumbra pela proximidade da praia, pela beleza da paisagem.

O mundo dos privilegiados está exposto em diferentes abordagens do acidente: a rápida mobilização das autoridades, os bombeiros e policiais uniformizados, inseridos em veículos aquáticos e helicópteros que, pelo menos nas cenas apresentadas, parecem novos e eficientes, impecavelmente sinalizados. A bela paisagem não se limita ao local do acidente em si, mas a todo um enquadramento do drama: se na primeira situação vemos a cidade rica/civilizada indo até a região desvalida, na segunda matéria temos os vícios da cidade desvalida invadindo o espaço urbano privilegiado. De fato, as tomadas aéreas das praias e das escarpas da Avenida Niemayer, plasticamente perfeitas, poderiam se confundir com um material de divulgação turístico sobre as belezas da cidade, e de certa forma funcionam como se assim o fossem.

Da mesma forma que na matéria anterior, a qualidade do material apresentado segue o padrão do telejornalismo da emissora, mas alguns aspectos devem ser ressaltados, entre eles o uso de computação gráfica para recriar o acidente, e as características gerais dos entrevistados. Mas, ao contrário da reportagem sobre as calçadas malconservadas, as reclamações não são estritamente pontuais, com demandas sobre remendos ou reconstruções, e sim amplas, com críticas à atuação do Estado.

Também há diferenças significativas no tratamento dado aos indivíduos retratados na reportagem: enquanto as vítimas das calçadas inadequadas são expostas em seus piores momentos, as vítimas do desabamento são poupadas - os corpos ensacados, as fotos escolhidas a partir das melhores ocasiões (sempre longe do acidente), reforçando a ideia de vítimas permanente $x$ vítimas eventuais.

Analisadas comparativamente, a questão do grotesco assume proporções diferentes. Embora tenha um grande potencial para o grotesco, na notícia ele aparece como exceção, um desvio que é reinserido na norma 
nas matérias posteriores que repercutem o fato. Assim, a matéria do acidente é complementada nos dias posteriores com matérias sobre apurações dos culpados, reconstruções etc., conforme demanda o andamento do caso. Já a denúncia é o grotesco que permanece nas desculpas (incompletas e pouco válidas), ditas em tom monocórdio pelo noticiarista, induzindo a certeza de ausência de resultados e se consolidando como o grotesco que se eterniza.

Essa relação se aprofunda na análise comparativa dos entrevistados, que inicialmente parece semelhante, mas esconde o grotesco da resignação contida de quem tem muito pouco e expõe a indignação perplexa de quem, tendo conquistado (e não recebido) se sente traído por uma ordem pública incompetente. A comparação aponta que os telejornais desenvolvem seus próprios jogos de linguagem na cobertura do espaço urbano, indo além da simples apresentação dos fatos e situação, suas narrativas configuram representações convencionadas de espaços urbanos e grupos sociais, afetando a relação dos moradores destes espaços e/ou elementos destes grupos com o Estado e o Poder público. Essa questão se torna mais significativa quando lembramos que: "Não é que os enunciados reproduzam a forma dos fatos, é que nos acostumamos a pensar nos fatos do modo como são configurados nos enunciados" (Eco, 1980, p. 147, tradução nossa) $)^{14}$.

Neste processo, o trabalho jornalístico define a presença de marcos, atributos e valor aos fatos e às representações urbanas (o que é normal e o que é exceção), construindo ou orientando as interpretações sobre essa normalidade/anormalidade, a partir do qual se interpõem também o sentimento do que deve ser feito e do que não tem conserto e, portanto, deve continuar sendo ignorado.

Construído (re-construído) jornalisticamente, as mazelas diárias das calçadas inadequadas são re-conectados a um tempo social e reinseridos em um contexto mais amplo, adquirindo diferentes graus de visibilidade e importância, em reportagens que dão vida ao que está esquecido (a calçada-cilada da cidade não acolhedora) mas reinsere essa situação por meio de uma narrativa autoritária, que ao revelar também esconde (ou silencia) o próprio direito do cidadão a aquilo que reivindica. Em outra instância, o acidente da passarela para ciclista na Avenida Niemayer, adquire o status de drama, de marco de recuperação (da cidade, da moralidade pública) de algo que pode e será obrigatoriamente consertado e reconstruído. O mundo narrado deformado pela própria narrativa reinsere ou reafirma os limites urbanos, definindo a cidade bela e a cidade grotesca.

Na justaposição destes dois elementos está construído o verdadeiro sentido do grotesco, do qual a representação imagética grotesca é apenas um sintoma a mais. A cidade da civilidade negada e a cidade do prazer, uma interferindo na outra, mas sem um verdadeiro contato humano.

\section{Da calçada-cilada para a civilidade} negada: considerações finais

A representação do grotesco na televisão não ocorre por acaso, é uma resposta direta da presença do grotesco na sociedade e nas cidades: o grotesco da TV é espetacularizado, mas não criado, ele é fruto de uma sociedade grotesca, que se habitua a cenas diárias de exageros de dor, sofrimento, caos, insegurança, medo e morte. No entanto, esse processo não deve ser visto apenas como registro:
Há muito tempo se sabe que a linguagem não é apenas designativa, mas principalmente produtora de realidade. A mídia é, como a velha retórica, uma técnica política de linguagem, apenas potencializada ao modo de uma antropotécnica política quer dizer, de uma técnica formadora ou interventora na consciência humana - para requalificar a vida social, desde costumes e atitudes até crenças religiosas, em função da tecnologia e do mercado (Sodré, 2012, p. 26).

No caso específico das representações da cidade do telejornalismo, portanto, trata-se também de uma construção que reforça preconceitos e diferencia indivíduos, o que por sua vez se reflete na própria percepção destes indivíduos sobre seus direitos, ou sobre a cidadania.

Paiva (2014, p. 61) lembra que "o investimento no automóvel, na sua produção, e também possibilidade de circulação, com a implantação de grandes avenidas são parte de um projeto excludente, destinado aos que possuem condições financeiras de adquirir modelos velozes e potentes". A cidade grotesca produz ruas sem calçadas onde uns não podem caminhar e outros transitam em carros importados, uma cidade que está próxima (valoriza) os que possuem transporte privado, mas está longe (desvaloriza) os que precisam de transporte público, porque eles pertencem ao que é feio, sujo e pobre, e portanto devem ficar à margem e não incomodar a cidade (Morin, 2005).

Representada pelo telejornalismo, o grotesco da cidade ganha um formato de espetáculo, a cidade-palco construída a partir de uma estética que envolve apropriação das linguagens cinematográficas e televisivas. 
Mas esse é também um espetáculo que possui dois lados, ambos absolutamente necessários para a construção de uma representação e afirmação: a vida desejada e os desgastes dos eternos desejantes.

O ponto de referência marcado pelos extremos coordenam, de forma indireta, o planejamento urbanístico e a existência social, os lugares por onde muitos transitam, mas não moram, as moradias marcadas pelos centrais e pelos periféricos, os espaços desejados e os espaços desprezados por todos, inclusive pelo poder público.

Nesta relação, seguindo o aporte teórico apresentado por Sodré e Paiva (2002), o grotesco torna-se algo mais amplo que hibridização de universos culturais diferentes, torna-se a própria hibridização da sociedade desejada, a cidade limpa e repleta de serviços dos bairros, invadida pela miséria, pela falta de recursos, pela substituição da civilidade, pela falta de cuidado, pelo desprezo pela vida humana. Em outra perspectiva, torna-se a negação - ou a reafirmação do desejo - de uma cidade impossível, o desejo de que a cidade rica se estenda, mecanicamente, para os espaços onde predomina a falta de recursos e a estrutura urbana.

Neste processo o estético vira uma espécie de poesia às avessas e muitas vezes de mau gosto, que separa os que tudo têm e aos que tudo falta, mas que igualmente possibilita o desejo irreal, o sonho impossibilitado pela prática distorcida que dá aos que muito tem, mais (muito mais) do que aos que muito necessitam. Expostos como a negação da própria civilidade, o grotesco coloca em destaque referências forçadas ${ }^{15}$ e contradições, inferindo no receptor

[...] um outro estado da consciência, uma outra experiência de lucidez, que penetra a realidade das coisas, exibindo a sua convulsão, tirando-Ihes os véus do encobrimento. O grotesco pode tornar-se de fato uma radiografia, inquietante, surpreendente, às vezes risonha do real (Sodré; Paiva, 2002, p. 60).

Mas neste processo também o grotesco é o elemento exposto que oblitera a realidade das cidades que constroem (se constroem e são construídas pelas mídias) a partir de suas diferenças, nos extremos entre o ter e o que é negado, a fome e a escassez, o feio e o belo. A cidade representada torna-se assim a dupla cidade: a que oferece a civilização e o respeito, sendo, portanto, o espaço para a vida plena e para a cidadania; e a cidade que nega o básico aos seus moradores, sendo em si mesmo a negação da cidadania.

Não sendo antropologicamente espelho ${ }^{16}$, a mídia se impõe como a própria reorganizadora do processo de existência social, interferindo de forma impactante na construção e na vida na cidade, fazendo do grotesco o "espelho que reflete o id e os demônios das nossas estruturas [...] espelho em que a sociedade se olha e se oferece como espetáculo" (Sodré, 1973, p. 39).

Tem-se assim que o grotesco se insere não apenas como estética ou recurso para uma aproximação estratégica do telejornalismo com o gosto popular e tática para conquista de um público antes pouco valorizado, trata-se de uma percepção política da cidade, ou uma forma de reforçar suas diferenças internas, repetindo preconceitos que corroboram uma visão de exclusão social na qual, mais do que informar, o telejornalismo reforça um mapeamento urbano fundamentado em uma negatividade estética, que apoiando-se em elementos do grotesco, insere espaços e grupos sociais como in- dignos ou insuficientes, em um espectro que coloca em questão o próprio direito à cidadania.

\section{Referências}

BAHIA, Juarez. Jornal História e Técnica: História da Imprensa Brasileira. São Paulo: Editora Ática, 1990.

ECO, Umberto. El signo. Barcelona. Editorial Labor, 1980.

ENGELS, Friedrich. A situação da classe trabalhadora na Inglaterra. Lisboa: Presença, 1985.

KANT, Immanuel. Crítica do juízo. São Paulo, Abril Cultural, 1980.

Jornal Bom Dia Brasil, 22 de abril de 2016. Engenheiros apontam falhas graves em ciclovia que desabou no Rio. Disponível em: <http://g1.globo.com/bom-dia brasil/videos/t/edicoes/v/engenheiros-apontam-falhasgraves-em-ciclovia-que-desabou-no-rio/4973816/>. Acesso em: 12 Mai 2016.

Jornal Bom Dia Brasil.15 de abril de 2016. Calçadas mal conservadas dão origem à campanha pelo país (calçada cilada) - denúncia redes sociais deflagrada grupo corrida amiga. Disponível em: <http://g1.globo.com/bom-dia-brasil/ videos/t/edicoes/v/calcadas-mal-conservadas-dao-origema-campanha-pelo-pais/4958149/>. Acesso em: 14 Mai 2016.

MORIN, Edgar. Ciência com consciência. Rio de Janeiro: Bertrand Brasil, 2005.

PAIVA, Raquel. Expressões do Comum na cidade: a ocupação pela mobilidade. In: PAIVA, Raquel; TUZZO, 
Simone Antoniaci (Org.). Comunidade, mídia e cidade: possibilidades comunitárias na cidade de hoje. Goiânia: FIC/UFG, 2014, v. 2, p. 57-69.

PARK, R. E. Um roteiro de investigação sobre a cidade. In: VELHO, G. (Org.). 0 fenômeno urbano. Rio de Janeiro: Zahar, 1987.

PENA, Felipe. Teorias do jornalismo. 2º. ed. São Paulo: Contexto, 2008.

SELIGMANN-SILVA, M.. Testemunho e a Política da Memória: O Tempo depois das Catástrofes. In: Projeto História, Revista do Programa de Estudos Pós-Graduados em História e do Departamento de História da PUC-SP, no. 30, Guerra, Império e Revolução, pp. 31-78, jun. 2005.

SILVA, Marconi Oliveira da. 0 mundo dos fatos e a estrutura da linguagem - a notícia jornalística na perspectiva de Wittgenstein. Porto Alegre: Edipucrs, 1998. 173p. (Coleção Filosofia 67).

SINGER, Ben. Modernidade, hiperestímulo e o início do sensaciolnalismo popular. In: CHARNEY, Leo; SCHAWARTZ, Vanessa. $\mathbf{O}$ cinema e a invenção da vida moderna. São Paulo: Cosac \&Naify, 2001

SODRÉ, Muniz. A comunicação do grotesco: introdução à cultura de massa no Brasil. 3ed. Petrópolis: Vozes, 1973.

SODRÉ, Muniz. Entrevista com Muniz Sodré (JB). Imprensa em15/07/2002. Disponível em: <http://www. editorasulina.com.br/noticias_det_2.php?id=25>. Acesso em: 15 abril 2016.
SODRÉ, Muniz. Antropológica do Espelho: Uma teoria da comunicação linear e em rede. Petrópolis/RJ: Vozes, 2012.

SODRÉ, Muniz. A narração do fato: notas para uma teoria do acontecimento. Petrópolis: Vozes, 2009.

SODRÉ, Muniz; PAIVA, Raquel. 0 império do grotesco. Rio de Janeiro: Mauad, 2002.

TUCHMAN, Gaye. A objetividade como ritual estratégico: uma análise das noções de objetividade dos jornalistas. In:TRAQUINA, Nelson. Jornalismo: questões, teorias e “estórias". Lisboa: Vega, 1999.

\section{Notas}

1 Pós-Doutora em Comunicação pela Universidade Federal do Rio de Janeiro- UFRJ. Coordenadora do Programa de Pós-Graduação em Comunicação e Professora Efetiva da Universidade Federal de Goiás (FACOMB/Faculdade de Comunicação e Biblioteconomia - Universidade Federal de Goiás - Campus Samambaia/ Campus II, Goiânia (GO), Brasil, CEP: 74001-970). E-mail: anacarolina.temer@gmail.com.br.

2 Pós-Doutora e Doutora em Comunicação pela Universidade Federal do Rio de Janeiro - UFRJ. Coordenadora do Curso de Especialização em Assessoria de Comunicação e Marketing e Professora Efetiva do Programa de Pós-Graduação em Comunicação da Universidade Federal de Goiás - UFG. (FACOMB/Faculdade de Comunicação e Biblioteconomia - Universidade Federal de Goiás - Campus Samambaia/Campus II, Goiânia (GO), Brasil, CEP: 74001-970). E-mail: simonetuzzo@hotmail.com.
3 http://g1.globo.com/bom-dia-brasil/videos/t/edicoes/v/engenheiros-apontam-falhas-graves-em-ciclovia-que-desabou-no-rio/4973816/

4 http://g1.globo.com/bom-dia-brasil/videos/t/edicoes/v/calcadas-mal-conservadas-dao-origem-a-campanha-pelo-pais/4958149/

5 A análise inicial da questão está em $A$ situação da classe trabalhadora na Inglaterra, publicada originalmente em 1845, mas o conceito é retomado por Marx em $O$ Capital, publicado originalmente em 1867.

6 O termo é usado por Robert Ezra Park (1987), nos estudos desenvolvidos na 'Primeira Escola de Chicago', que vigorou entre 1915 e 1940. Essa corrente inaugura a reflexão sobre a cidade como objeto privilegiado de investigação, tratando-a como variável isolada, e traz como contribuições as teorias da Ecologia Humana, de Robert Park, e das Zonas Concêntricas, de Ernest Burgess. Sobre esse ponto, ver PARK, R. E. Um roteiro de investigação sobre a cidade. In: VELHO, G. (Org.). O fenômeno urbano. Rio de Janeiro: Zahar, 1987.

7 A partir do que Kant define como fatos em uma realidade objetiva dizem respeito ao que pode ser provado, seja mediante pura razão, seja por experiência, e no primeiro caso a partir dos dados teóricos ou práticos da razão (Kant, 1980, p. 91).

8 A notícia é a alma do jornalismo, seu elemento definidor [...] seu objeto e seu fim (Bahia, 1990, p.35); é o gênero jornalístico básico (Silva, 1998, p.15). 
9 O texto jornalístico pode ser retoricamente ficcional, mas não fictício, enquanto o literário comporta apenas o ficcional e o fictício (Sodré, 2009, p. 167).

10 Segundo a classificação de Tuchman, matérias Duras ou Factuais (perecíveis), podem ser Súbitas-Sem previsão, como tragédias, incêndios, acidentes; o que neste trabalho classificamos como notícias. A autora também enquadra nesta classificação matérias Em sequência, Fatos pré-programados, como o desenvolvimento de um campeonato, votação de uma nova lei, cobertura de um julgamento; e $E m$ desenvolvimento - Acontecimentos que geram fatos ex: resgate dos feridos após um acidente (Tuchman apud Pena, 2008).

11 Tradicionalmente, é o período de maior audiência, ou de maior audiência em potencial, da televisão. No Brasil considera-se horário nobre o período que vai das 19 às 22 horas.

12 Ainda seguindo a classificação de Tuchman, os fatos jornalísticos podem ser também classificados como Leves - Não perdem atualidade - ex.: jogos, exposições, inaugurações etc. (Tuchman apud Pena, 2008).

130 termo se refere a um segredo que é conhecido de muitos. Entende-se que a expressão surge a partir do personagem italiano Pulcinello, da antiga comédia napolitana, e pelo francês Polichinelle, igualmente um personagem satírico.
14 "No es que los enunciados reproduzcan la forma de los hechos, es que nos acostumbramos a pensar los hechos del modo como los han configurado los enunciados".

15 Adaptações de uma cultura, ou uma manifestação cultural, a outra cultura a qual não pertence. Um exemplo seria, nas Folias de Rei, as Rainhas desfilarem com "vestidos de noiva" e seus adereços.

\section{Referência ao livro Antropológica do espelho:} uma teoria da comunicação linear em rede. Petrópolis (RJ): Vozes, 2002, de Muniz Sodré. 